\title{
A Highly Sensitive Nonenzymatic Glucose Biosensor Based on the Regulatory Effect of Glucose on Electrochemical Behaviors of Colloidal Silver Nanoparticles on $\mathrm{MoS}_{2}{ }^{\dagger}$
}

\author{
Kash Anderson ${ }^{1}$, Benjamin Poulter ${ }^{1}$, John Dudgeon ${ }^{2}$, Shu-En Li ${ }^{1}$ and Xiang Ma ${ }^{1,3, *}$ \\ 1 Department of Chemistry, Idaho State University, Pocatello, ID 83201, USA; andekas2@isu.edu (K.A.); \\ poulbenj@isu.edu (B.P.); lishue@isu.edu (S.-E.L.) \\ 2 Department of Anthropology, Idaho State University, Pocatello, ID 83201, USA; dudgeon@isu.edu \\ 3 Present address: Department of Chemistry, Grand View University, Des Moines, IA 50316, USA \\ * Correspondence: maxian@isu.edu or max@umail.iu.edu; Tel.: +1-208-282-2668 \\ $+\quad$ This paper is an extended version of our paper published in Ma, X. A Highly Sensitive Non-Enzymatic \\ Glucose Biosensor Based on Regulatory Effect of Glucose on Electrochemical Behaviors of Colloidal Silver \\ Nanoparticles on $\mathrm{MoS}_{2}$. In Proceedings of the 3rd International Electronic Conference on Sensors and \\ Applications, 15-30 November 2016.
}

Received: 31 May 2017; Accepted: 26 July 2017; Published: 5 August 2017

\begin{abstract}
A novel and highly sensitive nonenzymatic glucose biosensor was developed by nucleating colloidal silver nanoparticles (AgNPs) on $\mathrm{MoS}_{2}$. The facile fabrication method, high reproducibility $(97.5 \%)$ and stability indicates a promising capability for large-scale manufacturing. Additionally, the excellent sensitivity $\left(9044.6 \mu \mathrm{A} \cdot \mathrm{mM}^{-1} \cdot \mathrm{cm}^{-2}\right)$, low detection limit $(0.03 \mu \mathrm{M})$, appropriate linear range of $0.1-1000 \mu \mathrm{M}$, and high selectivity suggests that this biosensor has a great potential to be applied for noninvasive glucose detection in human body fluids, such as sweat and saliva.
\end{abstract}

Keywords: glucose biosensor; nonenzymatic; colloidal silver nanoparticle; molybdenum disulfide

\section{Introduction}

As of 2015, 415 million people suffer from diabetes worldwide, and 318 million people are at high risk of developing the disease in the future [1]. Diabetes is a chronic medical condition in which levels of glucose in the blood are raised significantly from the normal range. The high levels of glucose in the blood will eventually cause damage to many tissues in the body, including heart, eyes, kidneys and nerves, leading to painful and life-threatening health complications. According to the International Diabetes Federation, every six seconds a person dies from the health complications associated with diabetes. However, these complications can be prevented or controlled by monitoring blood glucose levels. Accordingly, millions of diabetics test their blood glucose levels daily, which makes glucose the most commonly tested analyte [2].

Since the first invention of glucose enzyme electrodes by Clark and Lyons in 1962 [3], a tremendous amount of research has been dedicated in developing enzyme-based biosensors [4-7], which rely on the catalytic activity of glucose oxidase (GOx) towards glucose in the blood [8-19]. However, this strategy has two fundamental drawbacks: first, the painful blood drawing process may prevent patients from their daily (or more frequently) blood sample testing; and second, the GOx enzyme is relatively fragile and expensive. Recent studies have showed a strong correlation between the glucose levels in human blood and those in other body fluids, such as sweat [20] and saliva [21]. For example, sweat glucose that was properly harvested to prevent contamination from other sources on the skin accurately reflected the blood glucose levels of patients [20]. The concentrations of glucose in these biofluids 
are in the $\mu \mathrm{M}$ range $[20,22]$. Thus, the development of nonintrusive, inexpensive and nonenzymatic glucose biosensors that are sensitive enough to effectively detect glucose in alternative body fluids of sweat and saliva is in great need.

$\mathrm{MoS}_{2}$ (molybdenum disulfide), a two-dimensional material with large surface area, rich surface chemistry, excellent biocompatibility, and a weakly bonded and layered structure, has attracted scientists' attention in a variety of fields in recent years [23-33]. While the unique atomic structure of $\mathrm{MoS}_{2}$ allows easy intercalation of metal atoms or ions [34,35], $\mathrm{MoS}_{2}$-based electrochemical devices suffer from unsatisfactory performance due to its poor intrinsic conductivity. As such, conductive additives have been employed to improve the electrochemical performance of $\mathrm{MoS}_{2}$ [36-38]. In this context, introducing noble metal nanoparticles, such as silver [39], as a conductive additive shall address this inadequacy and achieve an improved electrochemical performance.

Here, colloidal AgNPs were synthesized in the presence of $\mathrm{MoS}_{2}$, which was used to fabricate highly sensitive, nonenzymatic biosensors for the detection of relatively low glucose levels in human sweat and saliva. To our best knowledge, this is the first report of colloidal AgNPs $/ \mathrm{MoS}_{2}$-based nonenzymatic glucose biosensor.

\section{Materials and Methods}

\subsection{Reagents and Materials}

Silver nitrite $\left(>99 \% \mathrm{AgNO}_{3}\right)$, sodium borohydride $\left(99 \% \mathrm{NaBH}_{4}\right)$, glucose, glycine, urea, L-phenylalanine, L-lactic acid and L-tyrosine were purchased from Sigma-Aldrich (St. Louis, MO, USA). $\mathrm{MoS}_{2}$ powder $(10-30 \mu \mathrm{m})$ was obtained from Rose Mill Co. (West Hartford, CT, USA). All other reagents and chemicals were of analytical grade and were used as received without further purification.

\subsection{Preparation of $\mathrm{AgNPs} / \mathrm{MoS}_{2}$ Modified Electrodes}

The $\mathrm{MoS}_{2}$ powder was added to deionized water at an initial concentration of $50 \mathrm{mg} \cdot \mathrm{mL}^{-1}$, and then subjected to sonication at $500 \mathrm{~W}$ for $60 \mathrm{~min}$. The obtained slurry was set overnight. Then the supernatant was collected and mixed with $\mathrm{AgNO}_{3}$. The mixture, containing $1.0 \mathrm{mM} \mathrm{AgNO}$, was added dropwise to $2.0 \mathrm{mM} \mathrm{NaBH}_{4}$ that had been cooled in an ice bath, while stirred vigorously. When the solution turned light yellow, any further addition of the mixture and stirring was stopped immediately. The clear yellow solution was stable at room temperature when stored in a sealed vial in the dark for several months. The yellow solution of $\mathrm{AgNPs} / \mathrm{MoS}_{2}$ was used for electrode modification and subjected to structural characterizations later.

The AgNPs $/ \mathrm{MoS}_{2}$ modified electrode was fabricated by coating various amounts of $\mathrm{AgNPs} / \mathrm{MoS}_{2}$ solution onto the surface of polished glassy carbon (GC) electrodes. $20 \mu \mathrm{L}$ of AgNPs/MoS 2 gave the highest electrochemical response. After an overnight drying process, the electrode was carefully rinsed with water, dried again at room temperature, and then used for electrochemical measurements.

\subsection{Electrochemical Measurements}

Electrochemical measurements were performed on a PGSTAT204 electrochemical workstation (Metrohm, Houston, TX, USA) in a three-electrode electrochemical cell at room temperature of $25^{\circ} \mathrm{C}$. The AgNPs or AgNPs $/ \mathrm{MoS}_{2}$-modified GC electrode was used as the working electrode, $\mathrm{Ag} / \mathrm{AgCl}$ as the reference electrode, and $\mathrm{Pt}$ wire as the counter electrode. CVs (cyclic voltammetry) were obtained with a potential window of -0.50 to $0.50 \mathrm{~V}$ (vs. $\mathrm{Ag} / \mathrm{AgCl}$ ) in $0.1 \mathrm{M} \mathrm{NaOH}$ solution. SWV (square wave voltammetry) measurements were carried out with a potential window of $0.10-0.60 \mathrm{~V}(\mathrm{vs} . \mathrm{Ag} / \mathrm{AgCl})$ in $0.1 \mathrm{M} \mathrm{NaOH}$ solution at a frequency of $10 \mathrm{~Hz}$. A magnetic stirring was applied to the solution during SWV measurements to achieve convective mass transfer. 


\subsection{Materials Characterization}

UV-Vis absorption spectroscopic measurements were performed using Evolution 300 UV-Vis spectrophotometer (Thermo Fisher Scientific, Waltham, MA, USA). The morphology of the AgNPs $/ \mathrm{MoS}_{2}$ modified electrode was determined using scanning electron microscopy (SEM) (LEO 1430 VP, Carl Zeiss, Oberkochen, Germany), energy-dispersive X-ray (EDS) analysis, and atomic force microscopy (AFM) (Nexus One, NT-MDT, Tempe, AZ, USA). AFM measurements were performed in $\mathrm{AC}$ mode in $0.1 \mathrm{M} \mathrm{NaOH}$ solution with and without $1 \mathrm{mM}$ glucose at room temperature on freshly cleaved mica.

\subsection{Real Sample Collection and Preparation}

One male participant was recruited for this study. Written consent was sought prior to commencement of the study and ethical approval was provided by the Human Subjects Committee, Idaho State University, US (Reference IRB-FY2017-304).

Saliva samples $(\sim 1 \mathrm{~mL})$ were collected using a passive drool method without stimulation. Samples were collected into plastic vials and stored at $-20{ }^{\circ} \mathrm{C}$ until analysis. After thawing and centrifugation, the samples were diluted 1:1 volume ratio with $0.2 \mathrm{M} \mathrm{NaOH}$ solutions so that the final concentration of $\mathrm{NaOH}$ was $0.1 \mathrm{M}$. $0.1 \mathrm{M} \mathrm{NaOH}$ was chosen as a standard testing solution, because it removes concerns about the impact of $\mathrm{pH}$ and ionic strength in different samples on the performance of the biosensor. However, alkaline solution may denature the biomolecules in samples, which may interfere with reliable detections of glucose. If large amount of denatured biomolecules, such as proteins, are observed, further purification steps (centrifugation, liquid chromatography, etc.) may be necessary.

\section{Results}

\subsection{Materials Characterization of the Biosensor}

SEM images of AgNPs/MoS 2 showed that AgNPs exhibited a three-dimensional porous network structure (Figure 1a). Clusters of AgNPs, with a diameter of 1-7 $\mu \mathrm{m}$, distributed unevenly on the surface. The size of the clusters was comparable to that of $\operatorname{MoS}_{2}$ flakes $(\sim 10 \mu \mathrm{m})$. The average diameter of AgNPs within the clusters was estimated to be $\sim 5 \mathrm{~nm}$, which was supported by UV-Vis spectrum (Figure 1b): the wavelength of the plasmon absorption maximum was near $390 \mathrm{~nm}$, indicating a particle size of $5 \mathrm{~nm}$ [40]. The EDS spectrum of the $\mathrm{AgNPs} / \mathrm{MoS}_{2}$ film confirmed the co-existence of $\mathrm{Ag}$ and Mo (molecular weight ratio of $\mathrm{Ag} / \mathrm{Mo}$ is 20:1), suggesting that AgNPs were nucleated on $\mathrm{MoS}_{2}$ layers. In solution AFM images also showed that AgNPs were firmly attached on $\mathrm{MoS}_{2}$, or otherwise, they would not be observed. (Figure S1). 

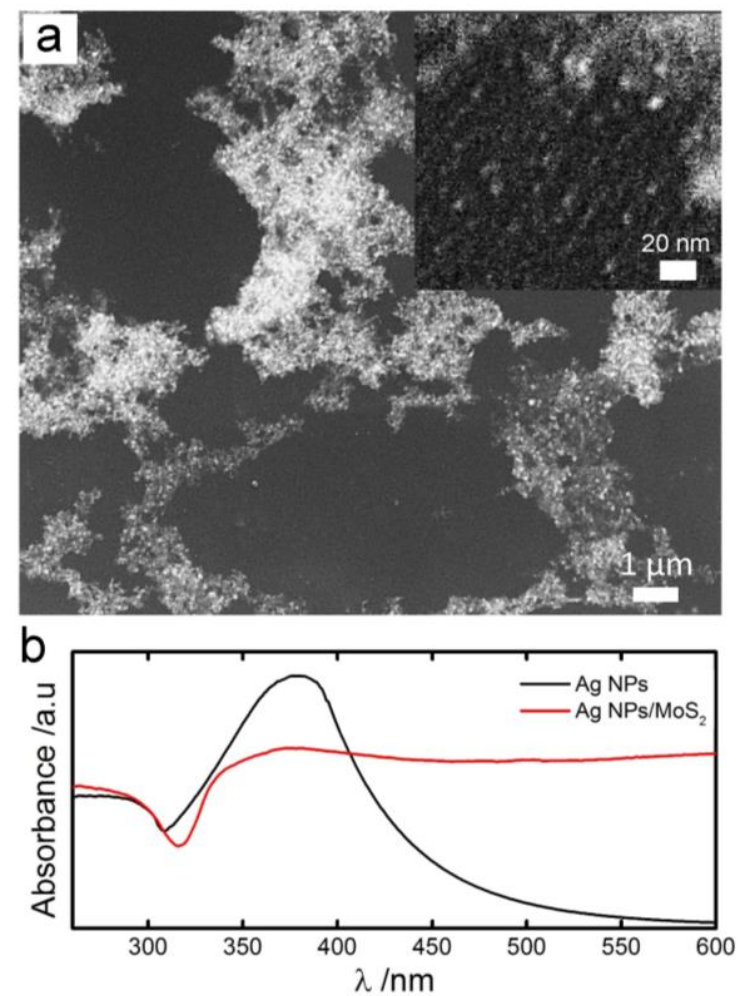

Figure 1. Materials Characterization. (a) Scanning electron microscopy (SEM) images of colloidal AgNPs nucleated on $\mathrm{MoS}_{2} ;$ (b) UV-Vis spectrum of AgNPs and AgNPs $/ \mathrm{MoS}_{2}$.

\subsection{Electrochemical Behavior}

Cyclic voltammograms (CVs) of the AgNPs and AgNPs/MoS 2 electrodes showed an enhanced electrochemical reactivity of AgNPs/MoS 2 compared with AgNPs only (Figure 2a). Two anodic peaks at 0.31 and $0.36 \mathrm{~V}$ (vs. $\mathrm{Ag} / \mathrm{AgCl}$ ) may represent the oxidation of $\mathrm{Ag}$ to $\mathrm{Ag}^{+}$and $\mathrm{Ag}^{+}$to $\mathrm{Ag}^{2+}$, while two cathodic peaks at -0.01 and $-0.04 \mathrm{~V}$ may be associated with the reversible conversion of $\mathrm{Ag}^{2+}$ back to Ag. The electrochemical redox phenomena of $\mathrm{Ag} / \mathrm{Ag}^{+} / \mathrm{Ag}^{2+}$ which occur at the working electrode surface in a basic solution can be represented as follows:

$$
\begin{gathered}
\mathrm{Ag}+\mathrm{OH}^{-} \leftrightarrow \mathrm{AgOH}+\mathrm{e}^{-} \\
\mathrm{AgOH}+\mathrm{OH}^{-} \leftrightarrow \mathrm{Ag}(\mathrm{OH})_{2}+\mathrm{e}^{-}
\end{gathered}
$$

$\mathrm{Ag}^{2+}$ normally requires a higher potential than $0.36 \mathrm{~V}$ to be generated. Here, we attribute the electrochemical signal at $0.36 \mathrm{~V}$ to the oxidation of $\mathrm{Ag}^{+}$to $\mathrm{Ag}^{2+}$, because when the size of AgNPs comes to the rage of $\sim 10 \mathrm{~nm}$, the activation energy required for the oxidation of $\mathrm{Ag}^{+}$to $\mathrm{Ag}^{2+}$ may be significantly reduced, potentially due to a decrease in interfacial energy and an increase in the portion of surface/interface atoms. However, other mechanistic representations may also be considered.

The potential scan rate $(v)$ was observed to be linearly related to the currents of both oxidation and reduction peaks (Figure 2b), a characteristic of diffusionless, thin-layer electrochemical behavior. The linear regression equations, $y=5.3636+1.6275 x$ and $y=-6.0773-1.6197 x$, and the regression coefficients, 0.9995 and 0.9987 , were obtained for oxidation and reduction peaks, respectively. In addition, the $E_{p a}$ and $E_{p c}$ are linearly dependent on the logarithm of the scan rate (Figure 2c). Laviron's model [41] gives:

$$
E_{p a}=E^{\theta}+\frac{R T}{(1-\alpha) n F} \ln \frac{(1-\alpha) F n v}{R T K_{s}}
$$




$$
\begin{gathered}
E_{p c}=E^{\theta}-\frac{R T}{\alpha n F} \ln \frac{\alpha F n v}{R T K_{s}} \\
\log k_{s}=\alpha \log (1-\alpha)+(1-\alpha) \log \alpha-\log \frac{R T}{n F v}-\frac{\alpha(1-\alpha) n F \Delta E_{p}}{2.3 R T}
\end{gathered}
$$

where $n$ is the number of electrons transferred in the rate determining step, $\Delta E_{p}$ is the peak potential separation, $v$ is the scan rate, and $R, T$, and $F$ are constants $\left(R=8.314 \mathrm{~J} \cdot \mathrm{mol}^{-1} \cdot \mathrm{K}^{-1}, T=298 \mathrm{~K}\right.$, $\left.F=96,485 \mathrm{C} \cdot \mathrm{mol}^{-1}\right)$. The electron-transfer coefficient $(\alpha)$ and apparent charge-transfer constant $\left(k_{s}\right)$ were thereby calculated to be 0.68 and $17.55 \mathrm{~s}^{-1}$, respectively, indicating that electron transfer was effectively promoted on the AgNPs $/ \mathrm{MoS}_{2}$ electrode.
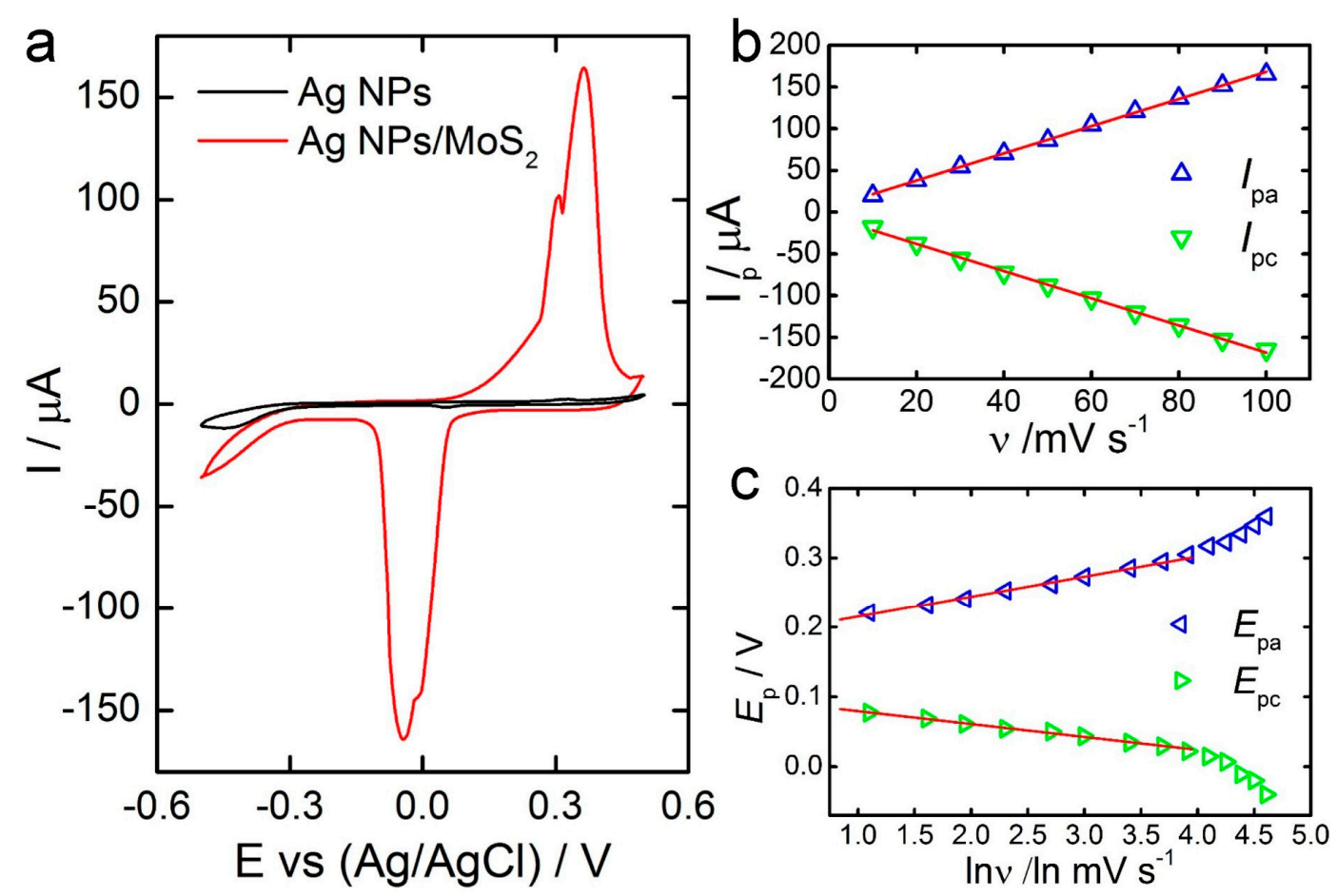

Figure 2. Electrochemical Characterization. (a) CV (cyclic voltammetry) curves of AgNPs and AgNPs $/ \mathrm{MoS}_{2}$ electrodes in $0.1 \mathrm{M} \mathrm{NaOH}$ at a scan rate of $0.1 \mathrm{~V} \cdot \mathrm{s}^{-1}$; (b) Peak currents versus scan rate $(v) ;(\mathbf{c})$ Peak potential versus $\ln v$.

\subsection{Glucose Detection}

Square wave voltammetry (SWV) was employed for the detection of glucose due to its high sensitivity and speed. After the electrode was stabilized in $0.1 \mathrm{M} \mathrm{NaOH}$ by running 10 times of SWV, solutions of glucose with different concentrations were added successively to the system. The current of the anodic peak decreased with increase of glucose concentrations (Figure 3a), suggesting an inhibitory effect of glucose on the electrochemical reactivity of the biosensor. This effect was reversible, as the biosensor regained its full electrochemical reactivity when the electrode was rinsed and inserted back into $0.1 \mathrm{M} \mathrm{NaOH}$ without glucose even after several repeated processes (Figure S2). We also observed that when the inhibitory effect was saturated (at a glucose concentration $>4 \mathrm{mM}$ ), the current of the anodic peak reached $8.0 \mu \mathrm{A}$, similar to the one of the electrode modified with AgNPs only (Figure 2a). In-solution AFM images showed that the thickness of $\mathrm{MoS}_{2}$ layers increased when glucose was added (Figure S1). These results imply that the regulation of the electrochemical reactivity by glucose takes effect by separating $\mathrm{MoS}_{2}$ layers, which prevents them from facilitating electron transfers between AgNPs and the electrode. Further studies are needed to determine detailed mechanisms of glucose regulation. 
The current-concentration curve (Figure $3 b$ ) showed a linear relationship in the range of $100 \mathrm{nM}$ to $1 \mathrm{mM}$ of glucose concentration, with a sensitivity of $9044.6 \mu \mathrm{A} \cdot \mathrm{mM}^{-1} \cdot \mathrm{cm}^{-2}$ $\left(\mathrm{I}(\mu \mathrm{A})=-0.284 \times \mathrm{C}(\mathrm{mM})+375.14\left(R^{2}=0.9995\right)\right)$. The limit of detection $(\mathrm{LoD})$ was estimated to be $0.03 \mu \mathrm{M}(\mathrm{S} / \mathrm{N}=3)$. This $\mathrm{LoD}$ is two orders lower than the glucose concentration in sweat and saliva in healthy patient, 8.3-120 $\mu \mathrm{M}[42,43]$. Therefore, the AgNPs $/ \mathrm{MoS}_{2}$ biosensor can be readily applied for noninvasive glucose detection in sweat and saliva. Both the sensitivity and LoD of the $\mathrm{AgNPs} / \mathrm{MoS}_{2}$ biosensor are superior to those of previously reported enzymatic and nonenzymatic biosensors (Table 1). We attribute the enhanced performance of the biosensor to high conductivity of Ag, large surface-to-volume ratio of the AgNPs nanostructure, large surface area of $\mathrm{MoS}_{2}$ and the precise regulation of glucose on electrochemical behaviors of AgNPs on $\mathrm{MoS}_{2}$.
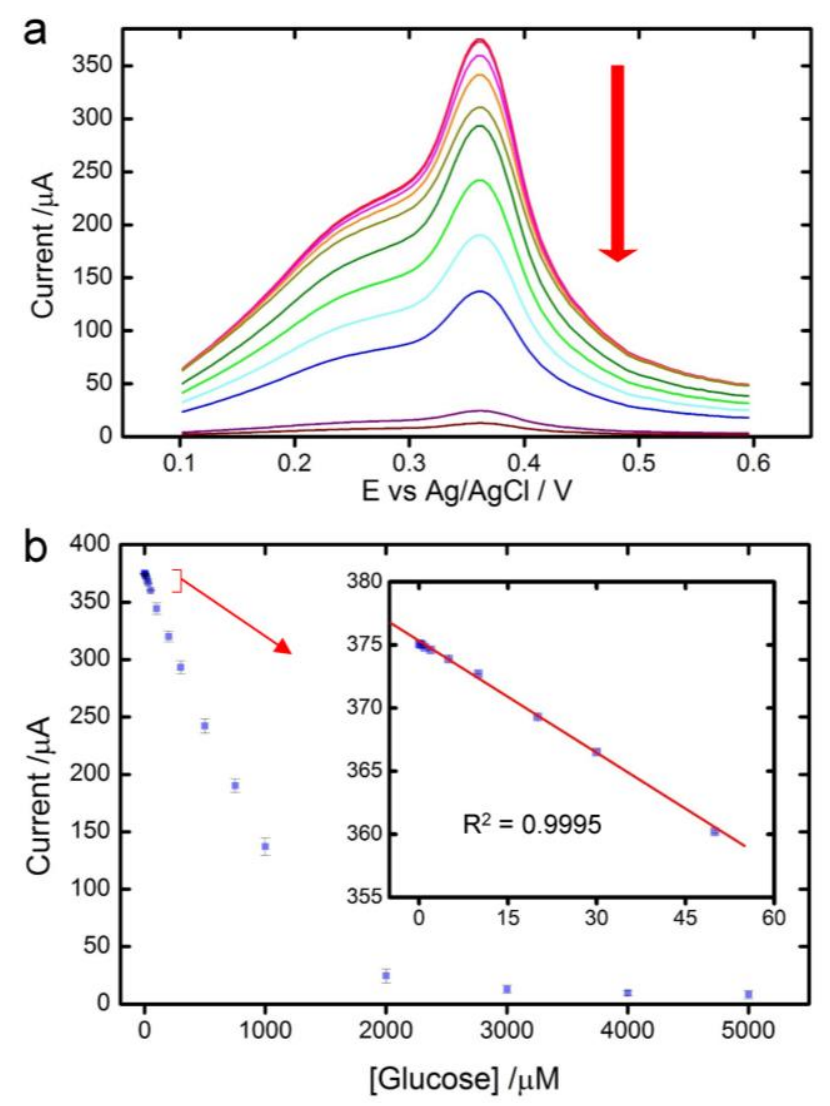

Figure 3. Glucose Detection. (a) Square wave voltammetry (SWV) curves of the AgNPs/MoS 2 electrode in $0.1 \mathrm{M} \mathrm{NaOH}$ containing $0.1,10,50,100,200,300,500,750,1000$ and $2000 \mu \mathrm{M}$ glucose, at a scan rate of $0.1 \mathrm{~V} \mathrm{~s}^{-1}$; (b) The calibration curves of the biosensor.

Table 1. Comparison of the performance of several electrochemical glucose biosensors.

\begin{tabular}{|c|c|c|c|c|}
\hline Sensor & $\operatorname{LoD}(\mu \mathrm{M})$ & Sensitivity $\left(\mu \mathrm{A} \cdot \mathrm{mM}^{-1} \cdot \mathrm{cm}^{-2}\right)$ & Linear Range $(\mu \mathrm{M})$ & Reference \\
\hline GC/Colloidal AgNPs/ $\mathrm{MoS}_{2}$ & 0.03 & 9044.6 & $0.1-1000$ & This work \\
\hline $\mathrm{GC} / \mathrm{Ag}-\mathrm{CNx}$ & 0.6 & 97 & $1-100$ & [44] \\
\hline $\mathrm{GC} / \mathrm{Cu}-\mathrm{Ag}_{2} \mathrm{O}$ NWs & 10 & 298.2 & $200-3200$ & [45] \\
\hline CuNCs-DLEG & 0.25 & 4532 & $25-4500$ & [46] \\
\hline $\mathrm{CuONPs} / \mathrm{Ag} / \mathrm{Si}$ & 0.5 & 2762.5 & $50-18,450$ & [47] \\
\hline Pt/AgTNPs/CHIT/GOx & 1 & 67.17 & 3-3000 & [48] \\
\hline rGO/PAMAM/Ag/GOx & 4.5 & 75.72 & $32-1890$ & [49] \\
\hline AgNWs/CS/GOx & 2.1 & 16.72 & $1000-15,000$ & {$[50]$} \\
\hline
\end{tabular}




\subsection{Selectivity, Stability and Reproducibility of the Biosensor}

Selectivity of the AgNPs/MoS 2 biosensor was evaluated by adding interfering substances commonly found in sweat and saliva, including $0.02 \mathrm{mM}$ glycine (Gly), urea, L-phenylalanine (L-Phe), L-lactic acid (L-LA), L-tyrosine (L-Tyr), ascorbic acid (VC), paracetamol (APAP), alcohol (EtOH) and $0.2 \mathrm{mM} \mathrm{NaCl}$ and $\mathrm{CaCl}_{2}$ into the system. The biosensor showed no response towards Gly, urea, L-Phe, L-LA, $\mathrm{NaCl}$ and $\mathrm{CaCl}_{2}$, and only slight response ( $<5 \%$ ) to L-Tyr and APAP (Figure 4a), indicating high selectivity of the biosensor towards glucose detection.

The stability and reproducibility of the biosensor were also evaluated. The stability was examined by recording 100 consecutive $\mathrm{CV}$ curves in $0.1 \mathrm{M} \mathrm{NaOH}$, and after the electrode was stored in the $4{ }^{\circ} \mathrm{C}$ refrigerator for 10 days. No obvious change in peak current was observed (Figure $4 b$ ), indicating a good stability of the biosensor. The reproducibility was examined by testing five different AgNPs $/ \mathrm{MoS}_{2}$ fabricated independently for their current response to glucose. From results shown in Figure $4 \mathrm{c}$, a reproducibility rate of $>97.5 \%$ is calculated, indicating that the biosensor is highly reproducible.
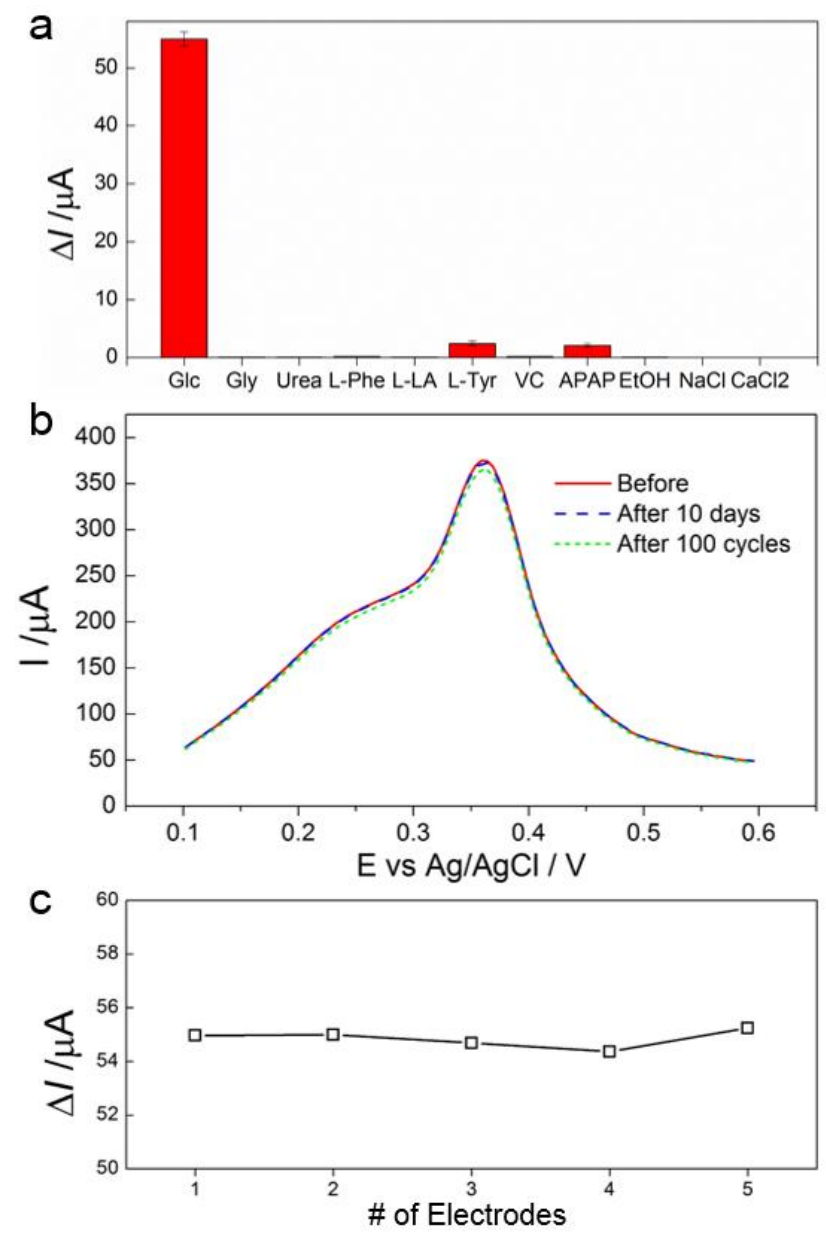

Figure 4. Selectivity, Stability and Reproducibility. (a) Changes of the peak current of the biosensor in the presence of $0.2 \mathrm{mM}$ glucose, $0.02 \mathrm{mM}$ Gly, urea, L-Phe, L-LA, L-Tyr, VC, APAP, EtOH and $0.2 \mathrm{mM} \mathrm{NaCl}$ and $\mathrm{CaCl}_{2}$; (b) SWV curves of the biosensor collected immediately after fabrication, after performing $100 \mathrm{CV}$ cycles, and after being stored in the $4{ }^{\circ} \mathrm{C}$ refrigerator for 10 days, in $0.1 \mathrm{M} \mathrm{NaOH}$; (c) Changes of the peak current recorded using five different biosensors in $0.1 \mathrm{M} \mathrm{NaOH}$ containing $0.2 \mathrm{mM}$ glucose. 


\subsection{Glucose Detection in Real Samples}

The practical application of the biosensor was evaluated by adding glucose to human sweat or saliva samples. The recovery tests were performed and the results were listed in Table 2 . The recoveries of the glucose concentration obtained by standard additions of glucose to real human samples ranged from $97 \%$ to $99.5 \%$. These results suggest that the AgNPs $/ \mathrm{MoS}_{2}$ biosensor can be used practically to detect glucose in real biological samples.

Table 2. Detection of glucose in human samples.

\begin{tabular}{|c|c|c|c|c|c|}
\hline Samples & $\begin{array}{l}\text { Glucose Concentration of Samples } \\
\qquad(\mu \mathrm{M})\end{array}$ & $\begin{array}{l}\text { Glucose Added } \\
\qquad(\mu \mathrm{M})\end{array}$ & $\begin{array}{l}\text { Glucose Found } \\
\qquad(\mu \mathrm{M})\end{array}$ & $\begin{array}{l}\text { Recovery } \\
\quad(\%)\end{array}$ & $\begin{array}{c}\text { RSD } \\
(\%)\end{array}$ \\
\hline \multirow{2}{*}{ Sweat } & \multirow{2}{*}{80.71} & 7 & 86.54 & 98.6 & 1.1 \\
\hline & & 100 & 179.82 & 99.5 & 1.1 \\
\hline \multirow{2}{*}{ Saliva } & \multirow{2}{*}{7.42} & 3 & 10.11 & 97.0 & 1.7 \\
\hline & & 20 & 27.02 & 98.5 & 1.3 \\
\hline
\end{tabular}

\section{Discussion and Conclusions}

A highly sensitive nonenzymatic glucose biosensor was developed using inexpensive fabrication method and biocompatible materials. The detection of glucose was achieved by a mechanism where glucose precisely regulates the electrochemical reactivity of AgNPs through potentially physical separation of AgNPs and $\mathrm{MoS}_{2}$. The porous nanostructures of AgNPs and large surface areas of $\mathrm{MoS}_{2}$ enhanced the interactive sites between AgNPs and electrode/glucose, contributing to accelerated electron transfer of AgNPs and the high sensitivity of the biosensor. The biosensor exhibited excellent sensitivity, stability and reproducibility, low LoD, and high selectivity, suggesting a novel candidate for noninvasive glucose monitoring for patients with diabetes. Further, the mechanism of action and facile fabrication method offer a novel approach for the development of other nonenzymatic biosensors and large-scale manufacturing. Future studies will be needed to employ the biosensor for in vivo and real time glucose detections.

Supplementary Materials: The following are available online at www.mdpi.com/1424-8220/17/8/1807/s1, Figure S1: Reversibility of the Regulatory Effect. The ratio of the peak current of the AgNPs/MoS 2 electrode after repeatedly performing glucose detection in the solution containing glucose and then being brought back to $0.1 \mathrm{M} \mathrm{NaOH}$, to the initial peak current. Figure S2: Reversibility of the Regulatory Effect. The ratio of the peak current of the Ag NPs $/ \mathrm{MoS}_{2}$ electrode after repeatedly performing glucose detection in the solution containing glucose and then being brought back to $0.1 \mathrm{M} \mathrm{NaOH}$, to the initial peak current.

Acknowledgments: This work was supported by the Department of Chemistry and Idaho State University. We thank Rene Rodriguez for his generous support.

Author Contributions: K.A. and X.M. conceived and designed the experiments; K.A. and X.M. performed the synthetic, electrochemical and UV-vis experiments; B.P. and J.D. performed SEM and EDS experiments; K.A., B.P. and X.M. analyzed the data; K.A., S.L. and X.M. wrote the paper.

Conflicts of Interest: The authors declare no conflict of interest.

\section{References}

1. Israel Defense Forces. International Diabetes Federation Diabetes Atlas, 7th ed.; International Diabetes Federation: Brussels, Belgium, 2015.

2. Xue, Z.; Huang, J.; Joseph, W. Electrochemical Sensors, Biosensors and Their Biomedical Applications, 1st ed.; Elsevier: Amsterdam, The Netherlands, 2008.

3. Clark, L.C.; Lyons, C. Electrode systems for continuous monitoring in cardiovascular surgery. Ann. N. Y. Acad. Sci. 1962, 102, 29-45. [CrossRef] [PubMed]

4. Li, C.; Tao, Y.; Yang, Y.; Xiang, Y.; Li, G. In vitro analysis of DNA—Protein interactions in gene transcription using dnazyme-based electrochemical assay. Anal. Chem. 2017, 89, 5003-5007. [CrossRef] [PubMed] 
5. Li, W.; Li, H.; Wu, S.; Feng, C.; Li, G. Highly sensitive protein detection based on dnazyme cycling activated surface assembly of peptide decorated nanoparticles. Electrochem. Commun. 2016, 71, 84-88. [CrossRef]

6. Huang, Y.; Li, H.; Wang, L.; Mao, X.; Li, G. Highly sensitive protein detection based on smart hybrid nanocomposite-controlled switch of DNA polymerase activity. ACS Appl. Mater. Interfaces 2016, 8, 28202-28207. [CrossRef] [PubMed]

7. Feng, C.; Mao, X.; Yang, Y.; Zhu, X.; Yin, Y.; Li, G. Rolling circle amplification in electrochemical biosensor with biomedical applications. J. Electroanal. Chem. 2016, 781, 223-232. [CrossRef]

8. Sternberg, R.; Barrau, M.-B.; Gangiotti, L.; Thévenot, D.R.; Bindra, D.S.; Wilson, G.S.; Velho, G.; Froguel, P.; Reach, G. Study and development of multilayer needle-type enzyme-based glucose microsensors. Biosensors 1989, 4, 27-40. [CrossRef]

9. Zhang, Y.; Wilson, G.S. In vitro and in vivo evaluation of oxygen effects on a glucose oxidase based implantable glucose sensor. Anal. Chim. Acta 1993, 281, 513-520. [CrossRef]

10. Liu, S.; Ju, H. Reagentless glucose biosensor based on direct electron transfer of glucose oxidase immobilized on colloidal gold modified carbon paste electrode. Biosens. Bioelectron. 2003, 19, 177-183. [CrossRef]

11. Feng, X.; Cheng, H.; Pan, Y.; Zheng, H. Development of glucose biosensors based on nanostructured graphene-conducting polyaniline composite. Biosens. Bioelectron. 2015, 70, 411-417. [CrossRef] [PubMed]

12. Han, L.; Shao, C.; Liang, B.; Liu, A. Genetically engineered phage-templated $\mathrm{MnO}_{2}$ nanowires: synthesis and their application in electrochemical glucose biosensor operated at neutral pH condition. ACS Appl. Mater. Interfaces 2016, 8, 13768-13776. [CrossRef] [PubMed]

13. Chaichi, M.J.; Ehsani, M. A novel glucose sensor based on immobilization of glucose oxidase on the chitosan-coated $\mathrm{Fe}_{3} \mathrm{O}_{4}$ nanoparticles and the luminol- $\mathrm{H}_{2} \mathrm{O}_{2}$-gold nanoparticle chemiluminescence detection system. Sens. Actuators B Chem. 2016, 223, 713-722. [CrossRef]

14. Hu, Y.; Liang, B.; Fang, L.; Ma, G.; Yang, G.; Zhu, Q.; Chen, S.; Ye, X. Antifouling zwitterionic coating via electrochemically mediated atom transfer radical polymerization on enzyme-based glucose sensors for long-time stability in $37^{\circ} \mathrm{C}$ serum. Langmuir 2016, 32, 11763-11770. [CrossRef] [PubMed]

15. Xu, J.; Sheng, Q.; Shen, Y.; Zheng, J. Enhanced direct electron transfer of glucose oxidase based on gold nanoprism and its application in biosensing. Colloids Surf. A Physicochem. Eng. Asp. 2017, 529, 113-118. [CrossRef]

16. Kausaite-Minkstimiene, A.; Simanaityte, R.; Ramanaviciene, A.; Glumbokaite, L.; Ramanavicius, A. Reagent-less amperometric glucose biosensor based on a graphite rod electrode layer-by-layer modified with 1, 10-phenanthroline-5, 6-dione and glucose oxidase. Talanta 2017, 171, 204-212. [CrossRef] [PubMed]

17. Shen, X.; Xia, X.; Du, Y.; Ye, W.; Wang, C. Amperometric glucose biosensor based on aupd modified reduced graphene oxide/polyimide film with glucose oxidase. J. Electrochem. Soc. 2017, 164, B285-B291. [CrossRef]

18. Mehmeti, E.; Stanković, D.M.; Chaiyo, S.; Zavasnik, J.; Žagar, K.; Kalcher, K. Wiring of glucose oxidase with graphene nanoribbons: An electrochemical third generation glucose biosensor. Microchim. Acta 2017, 184, 1127-1134. [CrossRef]

19. Gong, C.; Chen, J.; Song, Y.; Sun, M.; Song, Y.; Guo, Q.; Wang, L. A glucose biosensor based on the polymerization of aniline induced by a bio-interphase of glucose oxidase and horseradish peroxidase. Anal. Methods 2016, 8, 1513-1519. [CrossRef]

20. Moyer, J.; Wilson, D.; Finkelshtein, I.; Wong, B.; Potts, R. Correlation between sweat glucose and blood glucose in subjects with diabetes. Diabetes Technol. Ther. 2012, 14, 398-402. [CrossRef] [PubMed]

21. Panchbhai, A.S. Correlation of salivary glucose level with blood glucose level in diabetes mellitus. J. Oral Maxillofac. Res. 2012, 3. [CrossRef] [PubMed]

22. Jurysta, C.; Bulur, N.; Oguzhan, B.; Satman, I.; Yilmaz, T.M.; Malaisse, W.J.; Sener, A. Salivary glucose concentration and excretion in normal and diabetic subjects. BioMed Res. Int. 2009, 2009. [CrossRef] [PubMed]

23. Radisavljevic, B.; Radenovic, A.; Brivio, J.; Giacometti, I.V.; Kis, A. Single-layer $\mathrm{MoS}_{2}$ transistors. Nat. Nanotechnol. 2011, 6, 147-150. [CrossRef] [PubMed]

24. Yin, Z.; Li, H.; Li, H.; Jiang, L.; Shi, Y.; Sun, Y.; Lu, G.; Zhang, Q.; Chen, X.; Zhang, H. Single-Layer MoS Phototransistors. ACS Nano 2011, 6, 74-80. [CrossRef] [PubMed]

25. Lopez-Sanchez, O.; Lembke, D.; Kayci, M.; Radenovic, A.; Kis, A. Ultrasensitive photodetectors based on monolayer $\mathrm{MoS}_{2}$. Nat. Nanotechnol. 2013, 8, 497-501. [CrossRef] [PubMed] 
26. Chhowalla, M.; Amaratunga, G.A. Thin Films of Fullerene-Like $\mathrm{MoS}_{2}$ Nanoparticles with Ultra-Low Friction and Wear. Nature 2000, 407, 164-167. [CrossRef] [PubMed]

27. Wang, H.; Yu, L.; Lee, Y.-H.; Shi, Y.; Hsu, A.; Chin, M.L.; Li, L.-J.; Dubey, M.; Kong, J.; Palacios, T. Integrated circuits based on bilayer $\mathrm{MoS}_{2}$ transistors. Nano Lett. 2012, 12, 4674-4680. [CrossRef] [PubMed]

28. Acerce, M.; Voiry, D.; Chhowalla, M. Metallic $1 \mathrm{t}$ phase $\mathrm{MoS}_{2}$ nanosheets as supercapacitor electrode materials. Nat. Nanotechnol. 2015, 10, 313-318. [CrossRef] [PubMed]

29. Cui, X.; Lee, G.-H.; Kim, Y.D.; Arefe, G.; Huang, P.Y.; Lee, C.-H.; Chenet, D.A.; Zhang, X.; Wang, L.; Ye, F. Multi-terminal transport measurements of $\mathrm{MoS}_{2}$ using a van der Waals heterostructure device platform. Nat. Nanotechnol. 2015, 10, 534-540. [CrossRef] [PubMed]

30. Sangwan, V.K.; Jariwala, D.; Kim, I.S.; Chen, K.-S.; Marks, T.J.; Lauhon, L.J.; Hersam, M.C. Gate-Tunable Memristive Phenomena Mediated by Grain Boundaries in Single-Layer MoS 2 . Nat. Nanotechnol. 2015, 10, 403-406. [CrossRef] [PubMed]

31. Voiry, D.; Fullon, R.; Yang, J.; Silva, C.C.C.; Kappera, R.; Bozkurt, I.; Kaplan, D.; Lagos, M.J.; Batson, P.E.; Gupta, G.; et al. The role of electronic coupling between substrate and 2D $\mathrm{MoS}_{2}$ nanosheets in electrocatalytic production of hydrogen. Nat. Mater. 2016, 15, 1003-1009. [CrossRef] [PubMed]

32. Li, H.; Tsai, C.; Koh, A.L.; Cai, L.; Contryman, A.W.; Fragapane, A.H.; Zhao, J.; Han, H.S.; Manoharan, H.C.; Abild-Pedersen, F. Activating and optimizing $\mathrm{MoS}_{2}$ basal planes for hydrogen evolution through the formation of strained sulphur vacancies. Nat. Mater. 2016, 15, 48-53. [CrossRef] [PubMed]

33. Liu, C.; Kong, D.; Hsu, P.-C.; Yuan, H.; Lee, H.-W.; Liu, Y.; Wang, H.; Wang, S.; Yan, K.; Lin, D. Rapid water disinfection using vertically aligned $\mathrm{MoS}_{2}$ nanofilms and visible light. Nat. Nanotechnol. 2016, 11, 1098-1104. [CrossRef] [PubMed]

34. Woollam, J.A.; Somoano, R.B. Physics and chemistry of $\mathrm{MoS}_{2}$ intercalation compounds. Mater. Sci. Eng. 1977, 31, 289-295. [CrossRef]

35. Benavente, E.; Santa Ana, M.; Mendizábal, F.; González, G. Intercalation chemistry of molybdenum disulfide. Coord. Chem. Rev. 2002, 224, 87-109. [CrossRef]

36. Wang, J.Z.; Lu, L.; Lotya, M.; Coleman, J.N.; Chou, S.L.; Liu, H.K.; Minett, A.I.; Chen, J. Development of $\mathrm{MoS}_{2}-\mathrm{CNT}$ composite thin film from layered $\mathrm{MoS}_{2}$ for lithium batteries. Adv. Energy Mater. 2013, 3, $798-805$. [CrossRef]

37. Yu, H.; Ma, C.; Ge, B.; Chen, Y.; Xu, Z.; Zhu, C.; Li, C.; Ouyang, Q.; Gao, P.; Li, J. Three-Dimensional Hierarchical Architectures Constructed by Graphene/ $\mathrm{MoS}_{2}$ Nanoflake Arrays and Their Rapid Charging/Discharging properties as Lithium-Ion Battery Anodes. Chem. Eur. J. 2013, 19, 5818-5823. [CrossRef] [PubMed]

38. Pan, L.; Liu, Y.T.; Xie, X.M.; Zhu, X.D. Coordination-driven hierarchical assembly of silver nanoparticles on $\mathrm{MoS}_{2}$ nanosheets for improved lithium storage. Chem Asian J. 2014, 9, 1519-1524. [CrossRef] [PubMed]

39. Li, J.; Gao, T.; Gu, S.; Zhi, J.; Yang, J.; Li, G. An electrochemical biosensor for the assay of alpha-fetoprotein-L3 with practical applications. Biosens. Bioelectron. 2017, 87, 352-357. [CrossRef] [PubMed]

40. Baset, S.; Akbari, H.; Zeynali, H.; Shafie, M. Size measurement of metal and semiconductor nanoparticles via UV-Vis absorption spectra. Dig. J. Nanomater. Biostruct. 2011, 6, 709-716.

41. Laviron, E. General expression of the linear potential sweep voltammogram in the case of diffusionless electrochemical systems. J. Electroanal. Chem. Interfacial Electrochem. 1979, 101, 19-28. [CrossRef]

42. Yamaguchi, M.; Mitsumori, M.; Kano, Y. Noninvasively measuring blood glucose using saliva. IEEE Eng. Med. Biol. 1998, 17, 59-63. [CrossRef]

43. Makaram, P.; Owens, D.; Aceros, J. Trends in nanomaterial-based noninvasive diabetes sensing technologies. Diagnostics 2014, 4, 27-46. [CrossRef] [PubMed]

44. Kundu, M.K.; Sadhukhan, M.; Barman, S. Ordered assemblies of silver nanoparticles on carbon nitride sheets and their application in the nonenzymatic sensing of hydrogen peroxide and glucose. J. Mater. Chem. B 2015, 3, 1289-1300. [CrossRef]

45. Fang, B.; Gu, A.; Wang, G.; Wang, W.; Feng, Y.; Zhang, C.; Zhang, X. Silver oxide nanowalls grown on $\mathrm{Cu}$ substrate as an enzymeless glucose sensor. ACS Appl. Mater. Interfaces 2009, 1, 2829-2834. [CrossRef] [PubMed]

46. Tehrani, F.; Bavarian, B. Facile and scalable disposable sensor based on laser engraved graphene for electrochemical detection of glucose. Sci. Rep. 2016, 6. [CrossRef] [PubMed] 
47. Ahmad, R.; Vaseem, M.; Tripathy, N.; Hahn, Y.-B. Wide linear-range detecting nonenzymatic glucose biosensor based on $\mathrm{CuO}$ nanoparticles inkjet-printed on electrodes. Anal. Chem. 2013, 85, 10448-10454. [CrossRef] [PubMed]

48. Shi, W.; Ma, Z. Amperometric glucose biosensor based on a triangular silver nanoprisms/chitosan composite film as immobilization matrix. Biosens. Bioelectron. 2010, 26, 1098-1103. [CrossRef] [PubMed]

49. Luo, Z.; Yuwen, L.; Han, Y.; Tian, J.; Zhu, X.; Weng, L.; Wang, L. Reduced graphene oxide/pamam-silver nanoparticles nanocomposite modified electrode for direct electrochemistry of glucose oxidase and glucose sensing. Biosens. Bioelectron. 2012, 36, 179-185. [CrossRef] [PubMed]

50. Kumar-Krishnan, S.; Chakaravarthy, S.; Hernandez-Rangel, A.; Prokhorov, E.; Luna-Bárcenas, G.; Esparza, R.; Meyyappan, M. Chitosan supported silver nanowires as a platform for direct electrochemistry and highly sensitive electrochemical glucose biosensing. RSC Adv. 2016, 6, 20102-20108. [CrossRef]

2017 by the authors. Licensee MDPI, Basel, Switzerland. This article is an open access article distributed under the terms and conditions of the Creative Commons Attribution (CC BY) license (http://creativecommons.org/licenses/by/4.0/). 